\title{
Pediatric Blunt Thoracic Trauma
}

\author{
Hanna Alemayehu ${ }^{1}$ Pablo Aguayo ${ }^{1}$ \\ ${ }^{1}$ Department of Surgery, Children's Mercy Hospital and Clinics, Kansas \\ City, Missouri, United States \\ J Pediatr Intensive Care 2015;4:35-39.
}

Address for correspondence Pablo Aguayo, MD, Department of Surgery, The Children's Mercy Hospital, 2401 Gillham Road, Kansas City, MO 64108, United States (e-mail: paguayo@cmh.edu).

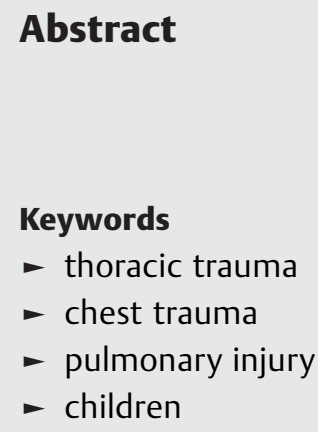

Thoracic injury in children deserves special attention because, although it accounts for less than $10 \%$ of traumatic injuries in children, there is a significant associated morbidity and mortality. This review discusses the anatomic and physiologic factors resulting in such injury severity with blunt thoracic trauma in children. Specific organ injuries, including most common chest wall injuries, hemo- and pneumothoraces, and pulmonary parenchymal injuries, are discussed, encompassing epidemiology, presentation, diagnosis, and management. Rare injuries including tracheobronchial tree injuries, cardiovascular injuries, esophageal injuries, and diaphragmatic injuries are also briefly discussed.

\section{Introduction}

Basic evaluation of an injured patient follows the tenets of the advanced trauma life support course, regardless of the patient's age. The primary survey establishes logical and sequential treatment priorities and identifies life-threatening conditions in the severely injured patient, ${ }^{1}$ and it speaks to the potential for life-threatening injury with thoracic trauma as the $A B C$ s of the primary survey can all be disrupted by trauma to the chest.

Thoracic injury in children deserves special attention because, although it accounts for less than $10 \%$ of traumatic injuries in children, there is a significant associated morbidity and mortality. ${ }^{2-5}$ In fact, chest trauma is the second most likely cause of death in children with traumatic injuries, ${ }^{2}$ and chest trauma in children is an indicator of increased mortality. ${ }^{5}$ Additionally, even though the small body surface area in children results in concomitant abdominal injuries, thoracic injuries are $20 \%$ more likely to be associated with death than abdominal injuries. ${ }^{2}$ Penetrating injuries to the chest in children are rare, and not included in this review.

Although chest wall injuries, hemothorax and pneumothorax, and pulmonary parenchymal injury are the most common pediatric thoracic injuries, ${ }^{6}$ this review will include a brief discussion of the more rare injuries of the tracheobronchial tree, great vessels, heart, esophagus and diaphragm, given their high morbidity and mortality.

\section{Anatomic and Physiologic Considerations}

The difference in morbidity and mortality between children and adults with thoracic trauma depends on several factors including anatomical and physiologic differences, differences in mechanism of injury, and differences in injury pattern. Children are more susceptible to thoracic trauma due to increased chest wall compliance as the ribs have not undergone complete ossification, and as they have decreased muscle mass. ${ }^{7}$ This results in increased transmission of force to the underlying organs during blunt force trauma, with relative preservation of the ribs as compared with adults. $3,8,9$ Additionally, the mediastinum is much more mobile in young children than in adults and accounts for an increased susceptibility to tension physiology and hypotension in the presence of pneumothorax, hemothorax, and diaphragmatic rupture. ${ }^{7,10}$

General physiologic differences between adults and children, such as higher metabolic rates, decreased functional residual capacity, larger body surface area to weight ratio, and cardiac output that is dependent on preload and heart rate, all predispose to hypoxemia, hypotension, and hypothermia, ${ }^{7,10,11}$ received

November 10, 2014 accepted after revision

November 27, 2014
Issue Theme Management of Children with Trauma in the PICU; Guest Editor: Pablo Aguayo, MD
DOI http://dx.doi.org/ 10.1055/s-0035-1554987. ISSN 2146-4618.
Copyright $\odot 2015$ by Georg Thieme Verlag KG, Stuttgart · New York 
resulting in significant morbidity and mortality in children with thoracic trauma.

Thoracic trauma in children most commonly results from motor vehicle related trauma, accounting for three quarters of blunt injuries to the chest, ${ }^{2}$ and includes both passengers in motor vehicles as well as pedestrian struck patients. In both cases, pediatric specific anatomy such as the chest being at the level of the bumper for pedestrian struck cases, ${ }^{6}$ or use of shoulder lap restraints or car seats in passengers, accounts for substantial thoracic injuries in children. ${ }^{12}$ Differences in injury pattern between children and adults also account for differences in thoracic trauma; children and adolescents are more likely to be involved in crashes with a higher change in velocity (delta $\mathrm{v}$ ) than adults, and predominantly suffer lung contusions or pneumothoraces. ${ }^{12}$ Both higher delta $\mathrm{v}$ and younger age are predictors of pulmonary injury. ${ }^{13}$ Additionally, although the increased chest compliance of children may be protective at crashes with lower delta $\mathrm{v}$, at higher delta $\mathrm{v}$ this increased compliance results in injury to underlying organs and tissues without associated rib fracturing. ${ }^{12}$ Since children are more likely to be involved in crashes with higher delta $\mathrm{v}$, they are therefore more susceptible to thoracic injury.

\section{Chest Wall Injury}

Rib fractures occur in 20 to $60 \%$ of children with thoracic trauma, but account for only 1 to $2 \%$ of trauma victims overall. $^{2,3,5,14-18}$ Flail chest occurs in only $1 \%$ of children with rib fractures, ${ }^{2}$ and operative repair is extremely uncommon. Patients may present with crepitus and subcutaneous emphysema, but more commonly with tenderness to palpation. Diagnosis can be made with plain X-ray and/or computed tomography (CT) of the thorax for definitive localization. Isolated rib fractures rarely require intervention other than aggressive pain management and pulmonary toilet to deter respiratory compromise secondary to limitation of ventilation by pain. Pain control maneuvers include systemic intravenous (IV) pain control and local transdermal analgesic patches; rarely more aggressive options are utilized such as intercostal regional blocks and epidural analgesia, depending on the extent of fracturing.

An important consideration with rib fractures in young children is the potential for nonaccidental trauma and physical abuse. In children younger than 3 years with rib fractures, particularly when other high energy mechanisms of trauma or predisposing medical pathology have been excluded, the workup should include evaluation by child abuse specialists after stabilization from a trauma standpoint: the positive predictive value of rib fractures for child abuse in this setting is $100 \%{ }^{19}$

\section{Hemothorax and Pneumothorax}

Up to $29 \%$ of children with chest trauma will sustain a hemothorax, up to $37 \%$ will sustain a pneumothorax, and up to $11 \%$ will have both. ${ }^{2,3,14}$ These injuries typically occur in conjunction with injuries to the lung parenchyma. As previously discussed, children with these injuries are particularly susceptible to cardiorespiratory compromise due to their increased chest wall compliance and mediastinal mobility. Minor pneumothoraces and hemothoraces may present with minor or no clinical symptoms. These are typically due to pulmonary parenchymal injury. ${ }^{20}$ They may be difficult to diagnose with chest X-ray, and are more commonly seen with CT scan; however, occult injuries that are only noted on CT scan rarely need intervention if there is no progression. Ultrasound diagnosis of simple pneumothoraces not seen on chest X-ray is nearly as sensitive as CT scan and can also be used for diagnosis. ${ }^{7}$ Moderate pneumothorax is diagnosed by chest X-ray and may require evacuation with tube thoracostomy, based on the clinical condition of the child. ${ }^{21}$ Hemothorax that has failed drainage with tube thoracostomy should be evacuated after 7 days, given the increased risk of posttraumatic empyema and restrictive lung disease ${ }^{7,22}$; thoracotomy or video assisted thoracoscopy can be performed, ${ }^{23}$ although the use of thrombolytics via the tube thoracostomy has also been suggested. ${ }^{7}$

Patients with tension pneumothorax present with respiratory distress, absent breath sounds, hyperresonance on percussion, jugular venous distension, and may have hemodynamic compromise from lack of venous return. These patients require immediate decompression with tube thoracostomy, and treatment should not be delayed for diagnostic imaging. A more significant pneumothorax-like symptom may be secondary to parenchymal injury, but clinicians should have a low threshold of suspicion for injury to the tracheobronchial tree. ${ }^{20}$

Patients with massive hemothorax will also have respiratory distress and absent breath sounds, however they will have dullness to percussion. They too may have the immediate symptoms of hypovolemia and hemorrhagic shock. Tube thoracostomy is required for decompression and treatment of respiratory distress, as well as to quantify blood loss and potential need for operative management. ${ }^{3,20}$ Transfusion of blood products should be initiated. Massive hemothorax is typically due to injury to intercostal vessels or significant parenchymal injury, but may be indicative of major vascular or cardiac injuries.

\section{Pulmonary Injury}

Direct lung injury from thoracic trauma is common in children due to the transmission of force through the relatively thin and compliant chest wall to the underlying organs; this results in pulmonary contusions, lacerations and traumatic pneumatoceles. Pulmonary contusions occur in 34 to $100 \%$ of children with thoracic trauma, 2,3,5,14-18 although they range in severity from being an isolated asymptomatic radiographic finding, to resulting in significant respiratory failure requiring mechanical ventilation. The pulmonary contusion results in damage at the level of the alveoli with hemorrhage and edema resulting in poor gas exchange., ${ }^{4,7}$ Diagnosis should be obtained by chest X-ray; although CT scan is more sensitive, it does capture clinically insignificant pulmonary contusions. Only the severity of lung contusion determined by chest X-ray, not CT scan, correlates with impairment of 
oxygenation, carbon dioxide exchange and duration of mechanical ventilation. ${ }^{24,25}$ Bedside ultrasonography to diagnose pulmonary contusion has also been described. ${ }^{26,27}$ Additionally, a negative chest X-ray does not preclude a significant pulmonary contusion, as these may develop several hours after injury. ${ }^{28}$ Minor pulmonary contusions require supportive care in the form of supplemental oxygen, pulmonary toilet and fluid restriction, however severe contusions may require mechanical ventilation in up to $30 \%$ of children. ${ }^{14,17,29,30}$ Additional strategies to maximize gas exchange may be required such as high positive end-expiratory pressures, inhaled nitric oxide, high frequency oscillating ventilation or even extra-corporeal membrane oxygenation. $^{31-33}$ Controversy exists in the literature regarding the morbidity of pulmonary contusions in children as compared with adults; some studies suggest that the morbidity in children is not as severe as in adults ${ }^{34,35}$; however, others show a similarly severe morbidity in terms of their overall injury severity, associated injuries, and outcomes. ${ }^{30}$ Nonetheless, long-term outcomes in children with pulmonary contusions show spontaneous resolution, and normal lung function in most children. ${ }^{17,36}$

When discussing pulmonary injury in the setting of trauma, adult respiratory distress syndrome often comes up. Although rare in children with traumatic injuries, it can occur and is most commonly due to polytrauma, shock or sepsis, rather than a result of direct trauma on the lung. ${ }^{30}$ When adult respiratory distress syndrome does develop, it carries an associated mortality of $62 \%$ in the pediatric population. ${ }^{37}$

Traumatic pneumatoceles are typically asymptomatic and can be diagnosed with visualization on chest X-ray or CT scan. They vary in size and typically require no intervention other than expectant management and repeat chest X-ray demonstrating a decrease in the size of the lesion, as they can sometimes increase in size for several days following injury. ${ }^{17,38,39}$ If they cause respiratory compromise due to significant increase in size, surgical resection is warranted. ${ }^{40}$

\section{Tracheobronchial Injury}

Injury to the tracheobronchial tree occurs in $<3 \%$ of children with thoracic trauma, but death occurs in about a third of these patients. ${ }^{41-43}$ The mechanism of this injury is usually from anteroposterior compression of the compliant chest wall pressing the sternum against the spine and resulting in lateral displacement of the lungs and injuring the bronchi or trachea at the carina. Additionally, there can be direct tracheal injury, or tracheobronchial injury from rapid rise in intratracheal pressure against a closed glottis from the force of the thoracic trauma. ${ }^{3}$

Patients may present asymptomatically, which can delay diagnosis, or they may present with pneumothorax, hemothorax, pneumomediastinum, hemoptysis, subcutaneous emphysema, and respiratory distress. ${ }^{3,43}$ Radiographic imaging is rarely helpful in diagnosing these injuries. Diagnosis is usually made when a continuous or large air leak develops and fails to resolve after tube thoracostomy, and flexible bronchoscopy confirms an injury. ${ }^{3}$ Bronchoscopy also guides management by allowing determination of location and extent of injury. If the patient remains stable from a respiratory point of view, if the airway can be secured (and the endotracheal tube passed beyond the injury), if the pneumothorax is evacuated, and the injury involves less than a third of the tracheal diameter, then the child can be managed nonoperatively. ${ }^{42,43}$ If thoracotomy and operative repair is required, the repair must be tension free to ensure success, and a vascularized tissue flap as reinforcement is recommended. ${ }^{3}$

\section{Cardiovascular Injury}

Injury to the great vessels and heart are rare in children, and occur less commonly than in adults. ${ }^{3}$ Thoracic aortic injuries occur in 1 to $7.4 \%$ of children with thoracic trauma, $2,3,14$ and blunt cardiac injury is even rarer occurring in 0.3 to $4.6 \%$ of children. ${ }^{44,45}$ These injuries have significant mortality with $30 \%$ mortality within 6 hours of arrival at the hospital with blunt aortic trauma and $40 \%$ in hospital mortality with cardiac trauma. ${ }^{3,46}$ Children with thoracic aortic injury present with first rib and sternal fractures, paraplegia, upper extremity hypertension, or pulse or blood pressure differentials in extremities. ${ }^{47,48}$ Aortic injury can be diagnosed with chest X-ray findings of widened mediastinum or loss of the aortic knob, and a CT scan with IV contrast should be performed in anyone with a suspicion of aortic injury. Transesophageal echocardiography and intravascular ultrasound can also be used. ${ }^{3}$ Prompt operative management with either open or endovascular approaches are mandatory (although in growing children endovascular stent grafts are less preferable), and aggressive blood pressure control should be implemented preoperatively.

Blunt cardiac injury may present as asymptomatic electrocardiography changes, arrhythmias, or profound hemodynamic compromise, depending on the severity of the injury. Echocardiography should be obtained in any patient with electrocardiography changes or who are symptomatic, and treatment remains supportive. ${ }^{44-46}$

\section{Esophageal Injury}

Esophageal perforation from blunt thoracic injury is very rare in children resulting in only a few cases having been described in the English language literature. ${ }^{49-54}$ Associated injuries are common and diagnosis can be difficult. Diagnosis is often delayed, because with blunt injury, as opposed to penetrating injury, the index of suspicion for esophageal injuries is typically low, and the associated signs and symptoms often also present in a delayed and nonspecific fashion, particularly if the injury is contained and presents later as an acquired tracheoesophageal fistula. The more common findings associated with esophageal perforations after blunt thoracic trauma include nonspecific neck and chest pain, dyspnea, fever, crepitance, subcutaneous air on plain film, pneumomediastinum and more rarely pleural effusions and pneumothoraces. ${ }^{54,55}$ These findings are nonspecific and can commonly be seen in other thoracic injuries, thereby, often resulting in delayed diagnosis of esophageal injuries. 
A high index of suspicion is required in these cases and full diagnostic work up should be undertaken if there is any concern for esophageal injury, or if there is an already diagnosed mediastinal injury; an almost 60\% incidence of concurrent tracheolaryngeal injury has been described in patients with an injury to the cervicothoracic esophagus, which is the most common site of esophageal injury. ${ }^{53,54}$ The potential for a delayed presentation, up to 74 days after injury in one pediatric case report, ${ }^{56}$ mandates that a previously negative diagnostic work up must be repeated if the suspicion for an injury persists.

Suspicion for esophageal injury should result in a watersoluble esophagram as the first diagnostic step as this avoids the potential inflammatory reaction of barium sulfate contrast; however, a negative study should be repeated with barium given a false negative rate of up to 10 to $38 \%$ with water-soluble contrast. ${ }^{55,57}$ Overall, the sensitivity of contrast radiographs for esophageal injuries (resulting from penetrating and blunt trauma) is reported at $97.4 \%{ }^{58}$ A negative contrast study, however, should be complemented with endoscopy. Furthermore, it is acceptable to perform endoscopy as the first diagnostic study depending on the stability of the patient and feasibility of transporting to the fluoroscopy suite, however, again using the contrast study as a complementary diagnostic modality if the esophagoscopy is negative.

Flexible endoscopy has the advantage of not requiring general anesthesia, being technically less challenging, and having a smaller complication rate than rigid esophagoscopy, however, rigid esophagoscopy has been reported to have a higher sensitivity ( $82 \%$ versus $37.5 \%$ in one of the largest published series, although, studies with smaller patient numbers have shown a sensitivity of $100 \%$ with flexible esophagoscopy). ${ }^{58}$ In children, rigid esophagoscopy is typically used as part of the armamentarium of the pediatric trauma surgeon. More recently, CT esophagography with the use of low-osmolar IV contrast material as the oral contrast agent has been suggested as a diagnostic modality instead of, or in conjunction with a negative fluoroscopic study. The advantage of this modality is that it evaluates for esophageal injury, but also for any other thoracic injury in the setting of trauma, that may result in the patient's presenting symptoms. ${ }^{57}$

Once the diagnosis has been made, nonoperative therapy should be used for stable patients with contained leaks. ${ }^{59,60}$ For those that fail nonoperative management, primary esophageal repair with live tissue reinforcement is ideal; however, in children with mediastinitis, a damage control operation with exclusion of the esophagus and drainage of the mediastinum should be performed. ${ }^{53}$

\section{Diaphragmatic Injury}

Diaphragmatic injuries are rare, but when they do occur, the left side is involved more frequently than the right due to the protection provided by the liver on the right. ${ }^{7,61-63}$ Children present with chest and shoulder pain, absent breath sounds on side of the injury, bowel sounds in the chest, respiratory distress, and abdominal pain. ${ }^{7,64}$
Diagnosis can be made with chest X-ray, however these injuries sometimes become apparent over time and so repeat imaging may be needed. ${ }^{61-63}$ Additionally, a normal chest X-ray does not rule out the injury, so in patients with a suspicion for diaphragmatic injury but no clear evidence on chest X-ray, chest CT with oral contrast can confirm the diagnosis, or if needed laparoscopy or thoracoscopy can be performed for diagnosis and treatment. ${ }^{3,61-63}$ Management entails operative repair typically via an abdominal approach in the acute setting, and a thoracic approach in the delayed setting. ${ }^{3}$ These injuries can be addressed with minimally invasive techniques (laparoscopy or thoracoscopy) in the stable patient.

\section{References}

1 Fildes J, Meredith JW, eds. American College of Surgeons Committee on Trauma. Advanced Trauma Life Support for Doctors. 8th ed. Chicago, IL: American College of Surgeons; 2008

2 Cooper A, Barlow B, DiScala C, String D. Mortality and truncal injury: the pediatric perspective. J Pediatr Surg 1994;29(1): 33-38

3 Sartorelli KH, Vane DW. The diagnosis and management of children with blunt injury of the chest. Semin Pediatr Surg 2004; 13(2):98-105

4 Tovar JA, Vazquez JJ. Management of chest trauma in children. Paediatr Respir Rev 2013;14(2):86-91

5 Peclet MH, Newman KD, Eichelberger MR, Gotschall CS, Garcia VF, Bowman LM. Thoracic trauma in children: an indicator of increased mortality. J Pediatr Surg 1990;25(9):961-965, discussion 965-966

6 Cooper A. Early assessment and management in trauma. In: Holcomb GW, Murphy JP, eds. Aschcraft's Pediatric Surgery. Philadelphia, PA: Elsevier; 2008:167-181

7 Puapong DP, Tuggle DW. Thoracic trauma. In: Holcomb GW, Murphy JP, eds. Aschcraft's Pediatric Surgery. Philadelphia, PA: Elsevier; 2008:167-181

8 Sarihan H, Abes M, Akyazici R, Cay A, Imamoglu M, Tasdelen I. Blunt thoracic trauma in children. J Cardiovasc Surg (Torino) 1996; 37(5):525-528

9 Shorr RM, Crittenden M, Indeck M, Hartunian SL, Rodriguez A. Blunt thoracic trauma. Analysis of 515 patients. Ann Surg 1987; 206(2):200-205

10 Kissoon N, Dreyer J, Walia M. Pediatric trauma: differences in pathophysiology, injury patterns and treatment compared with adult trauma. CMAJ 1990;142(1):27-34

11 Bliss D, Silen M. Pediatric thoracic trauma. Crit Care Med 2002;30 (11, Suppl):S409-S415

12 Arbogast KB, Locey CM, Zonfrillo MR. Differences in thoracic injury causation patterns between seat belt restrained children and adults. Ann Adv Automot Med 2012;56:213-221

13 O'Connor JV, Kufera JA, Kerns TJ, et al. Crash and occupant predictors of pulmonary contusion. J Trauma 2009;66(4): 1091-1095

14 Nakayama DK, Ramenofsky ML, Rowe MI. Chest injuries in childhood. Ann Surg 1989;210(6):770-775

15 Smyth BT. Chest trauma in children. J Pediatr Surg 1979;14(1): 41-47

16 Roux P, Fisher RM. Chest injuries in children: an analysis of 100 cases of blunt chest trauma from motor vehicle accidents. J Pediatr Surg 1992;27(5):551-555

17 Haxhija EQ Nöres H, Schober P, Höllwarth ME. Lung contusionlacerations after blunt thoracic trauma in children. Pediatr Surg Int 2004;20(6):412-414 
18 Balci AE, Kazez A, Eren S, Ayan E, Ozalp K, Eren MN. Blunt thoracic trauma in children: review of 137 cases. Eur J Cardiothorac Surg 2004;26(2):387-392

19 Barsness KA, Cha ES, Bensard DD, et al. The positive predictive value of rib fractures as an indicator of nonaccidental trauma in children. J Trauma 2003;54(6):1107-1110

20 Tovar JA. The lung and pediatric trauma. Semin Pediatr Surg 2008; 17(1):53-59

21 Genç A, Ozcan C, Erdener A, Mutaf O. Management of pneumothorax in children. J Cardiovasc Surg (Torino) 1998;39(6):849-851

22 Eren S, Esme H, Sehitogullari A, Durkan A. The risk factors and management of posttraumatic empyema in trauma patients. Injury 2008;39(1):44-49

23 Heniford BT, Carrillo EH, Spain DA, Sosa JL, Fulton RL, Richardson JD. The role of thoracoscopy in the management of retained thoracic collections after trauma. Ann Thorac Surg 1997;63(4): 940-943

24 Wylie J, Morrison GC, Nalk K, et al. Lung contusion in childrenearly computed tomography versus radiography. Pediatr Crit Care Med 2009;10(6):643-647

25 Kwon A, Sorrells DL Jr, Kurkchubasche AG, Cassese JA, Tracy TF Jr, Luks FI. Isolated computed tomography diagnosis of pulmonary contusion does not correlate with increased morbidity. J Pediatr Surg 2006;41(1):78-82, discussion 78-82

26 Soldati G, Testa A, Silva FR, Carbone L, Portale G, Silveri NG. Chest ultrasonography in lung contusion. Chest 2006;130(2):533-538

27 Stone MB, Secko MA. Bedside ultrasound diagnosis of pulmonary contusion. Pediatr Emerg Care 2009;25(12):854-855

28 Bonadio WA, Hellmich T. Post-traumatic pulmonary contusion in children. Ann Emerg Med 1989;18(10):1050-1052

29 Allen GS, Cox CS Jr. Pulmonary contusion in children: diagnosis and management. South Med J 1998;91(12):1099-1106

30 Allen GS, Cox CS Jr, Moore FA, Duke JH, Andrassy RJ. Pulmonary contusion: are children different? J Am Coll Surg 1997;185(3): 229-233

31 Marraro GA. Innovative practices of ventilatory support with pediatric patients. Pediatr Crit Care Med 2003;4(1):8-20

32 Ruddy RM. Trauma and the paediatric lung. Paediatr Respir Rev 2005;6(1):61-67

33 Fortenberry JD, Meier AH, Pettignano R, Heard M, Chambliss CR, Wulkan M. Extracorporeal life support for posttraumatic acute respiratory distress syndrome at a children's medical center. J Pediatr Surg 2003;38(8):1221-1226

34 Hamrick MC, Duhn RD, Carney DE, Boswell WC, Ochsner MG Pulmonary contusion in the pediatric population. Am Surg 2010; 76(7):721-724

35 Goedeke J, Boehm R, Dietz HG. Multiply trauma in children: pulmonary contusion does not necessarily lead to a worsening of the treatment success. Eur J Pediatr Surg 2014;24(6):508-513

36 Hoff SJ, Shotts SD, Eddy VA, Morris JA Jr. Outcome of isolated pulmonary contusion in blunt trauma patients. Am Surg 1994; 60(2):138-142

37 Davis SL, Furman DP, Costarino AT Jr. Adult respiratory distress syndrome in children: associated disease, clinical course, and predictors of death. J Pediatr 1993;123(1):35-45

38 Galea MH, Williams N, Mayell MJ. Traumatic pneumatocele. J Pediatr Surg 1992;27(12):1523-1524

39 Stathopoulos G, Chrysikopoulou E, Kalogeromitros A, et al. Bilateral traumatic pulmonary pseudocysts: case report and literature review. J Trauma 2002;53(5):993-996

40 Schimpl G, Schneider U. Traumatic pneumatoceles in an infant: case report and review of the literature. Eur J Pediatr Surg 1996; 6(2):104-106

41 Hancock BJ, Wiseman NE. Tracheobronchial injuries in children. J Pediatr Surg 1991;26(11):1316-1319
42 Slimane MA, Becmeur F, Aubert D, et al. Tracheobronchial ruptures from blunt thoracic trauma in children. J Pediatr Surg 1999; 34(12):1847-1850

43 Grant WJ, Meyers RL, Jaffe RL, Johnson DG. Tracheobronchial injuries after blunt chest trauma in children-hidden pathology. J Pediatr Surg 1998;33(11):1707-1711

44 Dowd MD, Krug S. Pediatric blunt cardiac injury: epidemiology, clinical features, and diagnosis. Pediatric Emergency Medicine Collaborative Research Committee: Working Group on Blunt Cardiac Injury. J Trauma 1996;40(1):61-67

45 Scorpio RJ, Wesson DE, Smith CR, Hu X, Spence LJ. Blunt cardiac injuries in children: a postmortem study. J Trauma 1996;41(2): 306-309

46 Kaptein YE, Talving P, Konstantinidis A, et al. Epidemiology of pediatric cardiac injuries: a National Trauma Data Bank analysis. J Pediatr Surg 2011;46(8):1564-1571

47 Hormuth D, Cefali D, Rouse T, Cutshaw J, Turner W Jr, Rodman G Jr. Traumatic disruption of the thoracic aorta in children. Arch Surg 1999;134(7):759-763

48 Karmy-Jones R, Hoffer E, Meissner M, Bloch RD. Management of traumatic rupture of the thoracic aorta in pediatric patients. Ann Thorac Surg 2003;75(5):1513-1517

49 Mukherjee K, Isbell JM, Yang E. Blunt posterior tracheal laceration and esophageal injury in a child. J Pediatr Surg 2009;44(6): 1292-1294

50 Uygun I, Otcu S, Aydogdu B, Okur MH, Arslan MS. Total esophageal avulsion at the esophagogastric junction after blunt trauma. Case Rep Surg 2013;2013:265073

51 Singhal AK, Bhatnagar V. Esophageal rupture secondary to blunt trauma in a child. Trop Gastroenterol 2004;25(1):42-43

52 Ein SH, Friedberg J, Chait P, Forte V, Najm H. Traumatic tear of aorta, trachea, and esophagus in a 7-year-old survivor. J Pediatr Surg 2002;37(1):E1

53 Sartorelli KH, McBride WJ, Vane DW. Perforation of the intrathoracic esophagus from blunt trauma in a child: case report and review of the literature. J Pediatr Surg 1999;34(3): 495-497

54 Beal SL, Pottmeyer EW, Spisso JM. Esophageal perforation following external blunt trauma. J Trauma 1988;28(10):1425-1432

55 Nirula R. Esophageal perforation. Surg Clin North Am 2014;94(1): 35-41

56 Wychulis AR, Ellis FH Jr, Andersen HA. Acquired nonmalignant esophagotracheobronchial fistula. Report of 36 cases. JAMA 1966; 196(2):117-122

57 Fadoo F, Ruiz DE, Dawn SK, Webb WR, Gotway MB. Helical CT esophagography for the evaluation of suspected esophageal perforation or rupture. AJR Am J Roentgenol 2004;182(5):1177-1179

58 Karmy-Jones R, Jurkovich GJ. Blunt chest trauma. Curr Probl Surg 2004;41(3):211-380

59 Martinez L, Rivas S, Hernández F, et al. Aggressive conservative treatment of esophageal perforations in children. J Pediatr Surg 2003;38(5):685-689

60 Garey CL, Laituri CA, Kaye AJ, et al. Esophageal perforation in children: a review of one institution's experience. J Surg Res 2010; 164(1):13-17

61 Rattan KN, Narang R, Rohilla S, Maggu S, Dhaulakhandi DB. Thirteen tears' experience of diaphragmatic injury in children from the post graduate institute of medical sciences (PGIMS), Rohtak, India. Malays J Med Sci 2011;18(1):45-51

62 Al-Salem AH. Traumatic diaphragmatic hernia in children. Pediatr Surg Int 2012;28(7):687-691

63 Okur MH, Uygun I, Arslan MS, et al. Traumatic diaphragmatic rupture in children. J Pediatr Surg 2014;49(3):420-423

64 Karnak I, Senocak ME, Tanyel FC, Büyükpamukçu N. Diaphragmatic injuries in childhood. Surg Today 2001;31(1):5-11 